\title{
Comment on Tuberculoma in the Medulla Oblongata and Medulla Spinalis: Two Case Reports
}

This is a well-written manuscript which underlines the importance of tuberculoma in developing countries and provides important data about the treatment of this entity (1).

In the first case, a surgical intervention was not mandatory because of the localization of the lesion, absence of hydrocephalus and lack of signs of brain stem compression (1). Although the surgery was succesful without any complication in this patient, generally we can not recommend surgery for brain stem tuberculoma due to the high risk of mortality and morbidity. The effectiveness of medical treatment has been reported many times in the literature for patients with tuberculoma in eloquent areas (2-5).

We do agree with the authors that the MRI scan of the patient is not typical for tuberculoma, and it is not possible to make the diagnosis of tuberculoma (6). However, there are some simple tests available to physicians to help their considerations of tuberculosis. The traditional simple skin test (ppd) still has $70-95 \%$ reliability. Moreover, quantiferon blood test can provide important information in relation to patients with suspected tuberculosis.

In the second case, we agree with surgery because there is mild compression to the spinal cord. The surgical intervention prevents paresis of the limbs and helps to confirm the diagnosis of tuberculoma in this patient.

We believe that the effectiveness and importance of medical treatment in tuberculosis should be stressed more strongly. In patients with such lesions where the exact diag- nosis of tuberculosis has not been made and where there is no evidence of neural tissue compression, the first choice may be anti-tuberculous medical treatment with close follow-up with the patient. Surgery may be performed when medical therapy is not sufficient and there are new signs of neural compression.

\section{Ali Fahir Özer \\ Department of Neurosurgery, Koç University School of Medicine, İstanbul, Turkey}

\section{References}

1. Gülşen S, Caner H. Tuberculoma in the Medulla Oblongata and Medulla Spinalis: Two Case Reports. Balkan Med J 2013;30:442-4.

2. Talamás $\mathrm{O}$, Del Brutto OH, García-Ramos G. Brain-stem tuberculoma. An analysis of 11 patients. Arch Neurol 1989;46:529-35. [CrossRef]

3. Gropper MR, Schulder M, Duran HL, Wolansky L. Cerebral tuberculosis with expansion into brainstem tuberculoma. Report of two cases. J Neurosurg 1994;81:927-31 [CrossRef]

4. Ertem DH, Aslan ND, Altunkaynak Y, Yıldız DS, Baybaş S. Isolated Brain Stem Tuberculoma: A Case Report and Review of The Literature. The Journal of Psychiatry and Neurological Sciences 2010;23:288-92.

5. Zein TM, Fletcher PS, Mirghani ZM. Intracranial tuberculoma. Neurosciences 2000;5:131-4.

6. Salgado P, Del Brutto OH, Talamás O, Zenteno MA, RodríguezCarbajal J. Intracranial tuberculoma: MR imaging. Neuroradiology 1989:31:299-302. [CrossRef] 